\title{
ADSORPTION OF INTAN-100 AT THE BITUMEN/AQUEOUS SOLUTION INTERFACE STUDIED BY SPINNING DROP TENSIOMETRY
}

\author{
M. Di Lorenzo ${ }^{1}$, H.T.M. Vinagre ${ }^{2}$, and D.D. Joseph ${ }^{2, *}$ \\ ${ }^{1}$ PDVSA-Intevep, Dept. of Production, P.O. Box 76343, Caracas 1070-A, Venezuela \\ ${ }^{2}$ University of Minnesota, Dept. of Aerospace Engineering \& Mechanics, Minneapolis, USA \\ * corresponding author: email: joseph@aem.umn.edu
}

\begin{abstract}
We present an experimental study on the adsorption behaviour of Intan-100, a nonionic surfactant, at the bitumen/water interface when the density difference between the two phases is increased by diluting the crude oil with $10 \%$ Xylene by weight or using heavy water (Deuterium Oxide) as the aqueous phase. Their equilibrium interfacial tension, surface excess and critical micelle concentration of Intan-100, at 30,60 and $75{ }^{\circ} \mathrm{C}$, are determined using a spinning drop tensiometer, which gives fast and accurate results for low and high values of the tension. Comparison with previous published data indicate that the use of heavy water is to be preferred over dilution of the heavy crude oil when the densities of the two phases are closely matched.
\end{abstract}

\section{Keywords}

Spinning Drop Tensiometer, bitumen, heavy water, Intan-100, Gibbs adsorption isotherm. 


\section{Introduction}

Adsorption and solution properties of surfactants are of special interest in the oil industry for applications in areas such as crude oil production, dehydration and emulsification [1]. The determination of the surfactant excess at the crude oil/water interface and the critical micelle concentration (C.M.C.) usually relies on interfacial tensiometric techniques, which allow the construction of Gibbs adsorption isotherms for these systems [2].

There are different devices that may be used to measure the interfacial tension under different conditions; no method is suitable for all conditions. The spinning drop tensiometer has advantages over other instruments when the contact of the interface with solid surfaces has to be avoided. Moreover the theory that supports this method has been worked out with exactitude and no empirical correction is needed to obtain reliable results [3]. In particular applications where low and ultra-low values of tension are achieved, the spinning drop is widely preferred over any other method. It has been argued that large tensions are not conveniently measured with this technique, but this is not true. If the apparatus is equipped with a motor that covers a wide speed range together with a testing tube of large dimensions, both high and low values of tension are reliably determined.

Shape methods for interfacial tension measurements are based on the equilibrium of capillary forces and forces due to an acceleration field, usually gravity [4]. . The pendant, sessile and spinning drop techniques are included in this category. Such methods require an accurate determination of the density difference between the two phases and are unavailing when the densities of the two liquids are perfectly matched. In this case, devices like the Wilhelmy plate, which do not depend directly on the density difference, cannot be used 
since the two fluids have to be arranged in layers. In principle, only Capillary Pressure methods can operate under this condition [5].

Measuring interfacial tension between extra-heavy crude oils like bitumen and aqueous surfactant solutions can be a difficult task. In fact these systems have usually densities that are closely matched, being the bitumen slightly heavier that water. Unfortunately bitumen has also extremely high viscosities, ranging from about $10^{6} \mathrm{mPa} \cdot \mathrm{s}$ at room temperature to $10^{3} \mathrm{mPa} \cdot \mathrm{s}$ at $75^{\circ} \mathrm{C}$, which restrict the application of techniques, such as the maximum drop pressure, based on the measurement of the Laplace pressure under flow through a capillary. If the temperature is not raised to very high values, the crude oil cannot be pumped and usually the Laplace pressure is barely detectable over the extremely high values of the viscous pressure drop across the capillary. Similar problems would be met if the water phase is injected into the external bitumen phase. Moreover this particular arrangement prevents checking, by visual inspection, that the capillary is not being wetted by the aqueous surfactant solution, condition which is crucial in order to obtain reproducible results. Pandit et al. [6] used this method to measure the interfacial tension of a Venezuelan bitumen, Cerro Negro Reconstituido (CNR), against water and aqueous solutions of the emulsifier Intan-100. They used high surfactant concentrations, of 0.5 and $0.75 \%$ weight, about three orders of magnitude above the C.M.C., at 75 and $90{ }^{\circ} \mathrm{C}$.

It is worth pointing out that the Capillary Pressure methods actually measure the tension under dynamic conditions and are not suitable for equilibrium measurements, when the kinetics of adsorption is slow, condition usually encountered at low surfactant concentrations. 
True equilibrium techniques are those based on the shape of drops under different conditions. Among these the sessile and pendant drop method are widely used. Nevertheless they do not give reproducible results when the density difference is too small to deform significantly the shape of the drop from the spherical shape under the action of the gravitational field. The pendant drop method has been applied to determine adsorption isotherms for CNR bitumen/aqueous solutions of Intan-100 [7] using a state of the art tensiometer which includes a computer image acquisition system to extract the drop contour to be fitted, afterwards, by numerical solutions of Young-Laplace equation. These quite advanced set up and data analysis are needed in order to detect very slight deviations of the drop edge from the circular shape, which is required at low surfactant concentration.

In this respect the spinning drop tensiometer is superior since it has a "controllable gravity" which can be raised, in principle, to arbitrarily high values by spinning faster. As mentioned before, conveniently designed instruments can give fast and reliable results in the whole range of interfacial tension values. Only one condition has to be fulfilled: the external phase has to be the heaviest and, of course, transparent to allow the observation of the inner droplet dimensions. This is usually achieved in common crude oil/water systems, except for bitumen. For this reason and in order to increase the density difference between the two phases, special techniques are needed which include, either dilution of the bitumen phase with a light fraction, or the use of heavy water $\left(\mathrm{D}_{2} \mathrm{O}\right)$ in place of $\mathrm{H}_{2} \mathrm{O}$ [8]. Deuterium oxide is about $10 \%$ heavier than water at room temperature.

In this paper we present a study of the adsorption of the surfactant Intan-100, the alkyl-phenol ethoxilated type, at the bitumen/aqueous solution interface at 30, 60 and 75 ${ }^{\circ} \mathrm{C}$, by using a spinning drop tensiometer designed at the University of Minnesota. Gibbs 
adsorption isotherms have been obtained for these systems using both a bitumen phase diluted with $10 \%$ Xylene by weight in contact with aqueous surfactant solutions and pure bitumen in contact with heavy water solutions. Important differences have been observed which are discussed in comparison with previously reported results.

\section{The Spinning Drop Tensiometer}

Modern image and data processing techniques can greatly enhance both the range and convenience of application of spinning drop devices. At the University of Minnesota a new Spinning Drop Tensiometer (SDT) has been developed, in which the live image of the droplet is displayed on a monitor. A schematic representation of the equipment is shown in Fig 1-A and a photograph is included in Fig. 1-B.

The measurements can be done either manually, using a reticule generator, or by a computer equipped with a frame grabber. Captured images can be enhanced and processed by the computer in the range of few seconds or stored for later analysis. From the images taken as a function of time, changes of the relevant dimensions of drop are detected by the computer very accurately, allowing to measure the interfacial tension temporal evolution. The relaxation of the drop is controlled by the tension and visco-elasticity of the interface and by bulk properties, such as the viscosity. The knowledge of the relaxation curves may provide a way to back out bulk or interfacial rheological parameters. The theory is not yet completely developed, but useful comparisons of relaxation data can be made even now.

The easy availability of drop shape data in the computerized device facilitates rapid acquisition of the diameter, length and volume of the drop as parameters for the analysis. Theoretical studies [9-10] indicate that the drop shape is determined by any two of these 
parameters. This frees the theoretical analysis from Vonnegut's formula [11] allowing to extract the equilibrium tension values from drops of any shape, from long elongated drops to short fat ones. When the density of the two fluid phases are very closely matched the drop will not elongate under the action of the centripetal field, remaining nearly spherical. Measurements under this condition require will be carried out soon.

The Spinning Drop Tensiometer (SDT) used in these experiments was described in detail by Joseph et al. [12] and in the US patent [13]. The tensiometer was designed so that it could be used to measure interfacial tension of common liquids and also in non conventional studies like those related with the use of compatibilizers in molten polymers blends. The SDT uses a rotating precision bore glass tube of $1.27 \mathrm{~cm}$ internal diameter with about $17 \mathrm{~cm}^{3}$ total volume, which can be easily loaded with the two fluids. The procedure consists, first, in pouring the external heaviest phase into the tube which is closed by a plug at one end. Afterwards, the other plug, specially designed to remove all the air inside the tube, is inserted. The drop phase is introduced through an orifice on this plug using a syringe with a large needle and finally the testing tube is sealed to complete the sample loading procedure. Bitumen tends to stick to the glass wall and this property facilitates the task to separate the drop from the needle and place it at the middle of the tube during the process of loading the sample and sealing the tube. Once the tube is rotating, if the density difference is large enough, the centripetal force will overcome the adhesion force and the lighter bitumen will be forced to the centre. The typical drop volume is in the range of 0.1 to $0.5 \mathrm{~cm}^{3}$. The testing tube is driven directly by the motor to eliminate vibrations. The speed range, $1,500-15,000 \mathrm{rpm}$, is usually more than enough to spread drops with the 
highest values of tension to reach arbitrarily large length to diameter ratios. The angular velocity is maintained well within $10 \mathrm{rpm}$ for a wide range of speeds.

The SDT is equipped with a convenient and compact open oven with a maximum temperature of $300{ }^{\circ} \mathrm{C}$. The temperature can be controlled to with $\pm 1{ }^{\circ} \mathrm{C}$. Spring loaded end caps are used to repressurize the sample which is depressurized by the centripetal acceleration; the repressurization is necessary to prevent the outgassing that occurs at high temperatures.

Measurements of interfacial tension on a spinning drop tensiometer are almost universally based on Vonnegut's formula [11]:

$$
\gamma=\frac{\left(\rho_{2}-\rho_{1}\right) \omega^{2} D^{3}}{32}
$$

where $\gamma(\mathrm{N} / \mathrm{m})$ is the interfacial tension, $\rho_{l}(\mathrm{~kg} / \mathrm{m} 3)$ is the density of the drop, $\rho_{2}$ is the density of the heavier fluid, $\omega(\mathrm{rad} / \mathrm{s})$ is the angular velocity of the rotating tube and $D(\mathrm{~m})$ is the diameter of the drop. Eq. 1 gives estimates for the tension with less than $0.05 \%$ error, under the assumption that the drop is in equilibrium and its length is more that four times its diameter.

We measure the drop diameters which are required to compute $\gamma$ from eq. 1 on a monitor screen. The field of views can be varied from 1 to $5 \mathrm{~mm}$ wide. A video measuring system superimposes an invisible grid on the top of the image and displays two movable reticules whose relative distance is always shown in a menu bar. The grid can be calibrated against a rod of known diameter so the reticules display the measurements in the desired units. The calibration rod has three steps of nominal diameters of 1.0, 2.0 and $3.0 \mathrm{~mm}$. The 
step with diameter closer to the drop diameter is used for calibration. Drop diameters can be measured to within an accuracy better than $\pm 0.03 \mathrm{~mm}$ by this method. For each fluid to be used in the measurements we fitted a polynomial for the density as a function of temperature. Therefore by setting the temperature, we obtain the density difference.

\section{Materials}

The CNR bitumen and the surfactant Intan-100 were provided by PDVSA-Intevep. CNR bitumen has a gravity of about $8.2^{\circ} \mathrm{API}$ and viscosity of $8.5 \times 10^{5} \mathrm{mPa} \cdot \mathrm{s}$ at $30{ }^{\circ} \mathrm{C}$ and $1.75 \times 10^{3} \mathrm{mPa} \cdot \mathrm{s}$ at $75{ }^{\circ} \mathrm{C}$. The surfactant is a nonyl-phenol-ethoxilated commercial surfactant, with an average of 17.5 ethylene oxide groups, which is used in the emulsification of the CNR bitumen to obtain Orimulsion ${ }^{\circledR}$, a product exported world wide as a liquid fuel for power stations. Intan-100 is highly soluble in water and almost insoluble in bitumen. The Xylene used for bitumen dilution, of reagent grade, was obtained from Aldrich Chemical. As water phases we used commercial distilled water from Kandiyohi Bottled Water Co. and Deuterium Oxide, 99.9\% D, from Cambridge Isotope Laboratories.

For the various fluids the density $\left(\mathrm{kg} / \mathrm{m}^{3}\right)$ as a function of temperature $T\left({ }^{\circ} \mathrm{C}\right), \rho(T)$, was fitted using the formula:

$$
\rho(T)=C_{0}+C_{1} T+C_{2} T^{2}+C_{3} T^{3}
$$

The coefficients $C_{i}$ are given in Table 1 . Those corresponding to CNR bitumen and to the bitumen $+10 \%$ Xylene mixture were obtained from density data provided by PDVSAIntevep. These were measured with a Density Meter Par, model DMA 512, Austria, in the temperature range between 20 to $80{ }^{\circ} \mathrm{C}$ with intervals of $10{ }^{\circ} \mathrm{C}$. The concentrations were 
varied from $100 \%$ (pure Xylene) up to $15 \%$ of Xylene in CNR bitumen by weight. Plotting the graphic of concentration vs. density, we extrapolated the linear region between $75 \%$ and $15 \%$ to $10 \%$ and 0 (pure CNR). Repeating this procedure for each temperature, we fitted those points using a least square routine to obtain the coefficients in Table 1 . The correlation coefficient was less than 0.9996.

The amount of Intan-100 added to the water to prepare the surfactant solutions used in this work was very small. Therefore it was assumed that these solutions have the same density of pure water or pure Deuterium Oxide. The density vs. temperature data for these liquids were extracted from the CRC Handbook of Chemistry and Physics [14] and the coefficients in Table 1 were obtained by interpolation, using the least square method.

\section{Results}

We present first the results obtained for the interfacial tensions of the different oil/water systems free of surfactant, as a function of temperature. These data are shown graphically in Fig.2. The interfacial tension between CNR bitumen diluted with Xylene and pure water was found to decrease from 15.7 to $13.5 \mathrm{mN}$ upon increasing the temperature from 30 to $60{ }^{\circ} \mathrm{C}$. These rather low values of the interfacial tension, as compared with those corresponding to pure oils, indicate the presence of naturally occurring surfactants which adsorb at the interface [15]. In Fig.2 are also reported the values of the tension of pure bitumen in contact with distilled water at different temperatures as determined in [16] and

[6] for comparison. These data are fitted by linear regression, as indicated in the same Figure. We can observe that dilution of the bitumen does not seem to have noticeable 
effects on the tension values, even if their rate of change with temperature seems to be lower with respect to the pure bitumen system.

A similar behavior of the tension with temperature can be observed in the case of the CNR bitumen in contact with heavy water, but the tension values are shifted upwards by about $9 \mathrm{mN} / \mathrm{m}$ in the case of the pure bitumen and about $11 \mathrm{mN} / \mathrm{m}$ for the diluted CNR. The linear equation which fits the $\mathrm{CNR} / \mathrm{D}_{2} \mathrm{O}$ data is also reported in Fig.2. The fact that the $\mathrm{CNR} / \mathrm{D}_{2} \mathrm{O}$ system presents much higher interfacial tensions than $\mathrm{CNR} / \mathrm{H}_{2} \mathrm{O}$ at the same temperature is quite remarkable, if we consider that surface tension of water and heavy water are the same to within $0.5 \%$. There seems to be a general consensus about the idea that the hydrophobic interactions are stronger in $\mathrm{D}_{2} \mathrm{O}$ that in $\mathrm{H}_{2} \mathrm{O}$ [17], but the consequences of using heavy water on the surfactant solution and adsorption properties are not well understood. Higher CMC and aggregation number values for ionic surfactants micelles, using Deuterium Oxide instead of water as a solvent, have been reported [17], but such effects have not been observed in the case of non-ionic surfactants [18].

Bitumen is a complex mixture of aromatic and aliphatic hydrocarbons which contain asphaltenic and resinous components with interfacial activity. They are associated in the crude by means of hydrogen bonding interactions and, once adsorbed at the interface, they could also be able to establish such interactions with the aqueous phase. In addition to hydrogen bonding, the presence of pi-orbitals in these organic compounds could also lead to a comparable effect. We can speculate that differences in the adsorption energy of natural surfactants in contact with water as compared with Deuterium Oxide may manifest as noticeable chances in the interfacial tension. 
Adsorption isotherms for Intan-100 at the interface bitumen $+X y l e n e / \mathrm{H}_{2} \mathrm{O}$ and bitumen/ $\mathrm{D}_{2} \mathrm{O}$ have been determined at 30,60 y $75{ }^{\circ} \mathrm{C}$. These are presented in Figs. 3-8. From these graphs the values of the surface excess at saturation, $\Gamma_{\infty}\left(\operatorname{moles} / \mathrm{cm}^{2}\right)$, the specific area per molecule, $A_{0}\left(\AA^{2}\right)$, the C.M.C. and the interfacial tension above the C.M.C., $\gamma_{\mathrm{CMC}}$, have been deduced. These results are summarized in Table 2. The surface excess is calculated from the slope of the tension vs. logarithm of the surfactant concentration line [2] obtained by interpolation of the experimental values. We estimate that values of the surface excess are affected by relative errors of about $10 \%$, mainly due to reproducibility errors produced by the complex character of our oil phase, impurities of the surfactant samples and accidental non avoidable contaminations. Errors on the C.M.C. are much more difficult to quantify, since these values are determined by inspection on the isotherms and depend strongly on the way the horizontal line interpolating points above the C.M.C. is traced. Our best estimates are indicated by an arrow on the respective adsorption isotherms.

Values of the superficial tension as a function of concentration for Intan-100 dissolved in $\mathrm{D}_{2} \mathrm{O}$ at 30,60 y $75^{\circ} \mathrm{C}$ are reported in Fig.9. In Fig. 10 the adsorption isotherm for Intan-100 at the interface air/ $\mathrm{H}_{2} \mathrm{O}$ together with values corresponding to the air/ $/ \mathrm{D}_{2} \mathrm{O}$ system at $30{ }^{\circ} \mathrm{C}$ are shown for comparison. Determination of the surface excess of Intan100 are carried out only at the air/ $\mathrm{H}_{2} \mathrm{O}$ interface at $30{ }^{\circ} \mathrm{C}$; the results are reported in Table 2.

The results obtained from the air/ $\mathrm{H}_{2} \mathrm{O}+\mathrm{Intan}-100$ isotherm can be compared with similar data reported by Schick et al. [19] for a nonylphenol (EO) 15 surfactant at $30{ }^{\circ} \mathrm{C}$. These authors found $A_{0}=65\left(\AA^{2}\right)$, C.M.C. $=1.0 \times 10^{-7}\left(\right.$ moles $\left./ \mathrm{cm}^{3}\right)$ and $\gamma_{\mathrm{CMC}}=37.0 \mathrm{mN} / \mathrm{m}$, 
values quite similar to ours, except for the Intan-100 area per molecule, which we found to be about $25 \%$ higher.

Results for the adsorption at the oil/Intan-100 aqueous solutions indicate that the surfactant film is in a more expanded state compared with the superficial film, as expected [20]. It has been reported a significant reduction in effectiveness of adsorption at the aqueous solution/hydrocarbon interface when increasing the aromatic content of the oil [20]. These findings are consistent with the increase of the specific area per adsorbed Intan100 molecule upon bitumen dilution with Xylene, as reported in Table 2.

Effects of the dilution show up also in the C.M.C. values: our data show clearly a remarkable shift to lower concentration values upon addition of Xylene. Depression of the C.M.C. in the presence of aromatic hydrocarbons has been previously reported [2]. The CMCs in the bitumen/ $/ \mathrm{D}_{2} \mathrm{O}$ system, on the other hand, are quite close to those found by us in air $/ \mathrm{H}_{2} \mathrm{O}$ and in air $/ \mathrm{D}_{2} \mathrm{O}$, about $1 \times 10^{-7}$ moles $/ \mathrm{cm}^{3}$. The same result has been reported for the C.M.C. in bitumen $/ \mathrm{H}_{2} \mathrm{O}+$ Intan-100 and heptane $/ \mathrm{H}_{2} \mathrm{O}+$ Intan-100 systems [7].

The presence of well pronounced minima at the C.M.C. in air $/ \mathrm{D}_{2} \mathrm{O}$ indicates the presence of impurities with high surface activity in the surfactant solution, such as short ethoxilated chain moieties. Intan-100 is a commercial surfactant with a quite wide molecular weight distribution. It is evident from our surface tension results that the mentioned effect is enhanced when $\mathrm{D}_{2} \mathrm{O}$ is used instead of water and this could be ascribed to the more hydrophobic character of heavy water as a solvent.

The surface excess and C.M.C values of Intan-100, in the limits of the experimental error, do not show a definite trend as a function of temperature, up to $75^{\circ} \mathrm{C}$, in any of the 
studied systems. Appreciable changes are expected at temperatures closer to the cloud point of this surfactant, which is about $120^{\circ} \mathrm{C}$.

\section{Conclusions}

Using a versatile spinning drop tensiometer developed at the University of Minnesota, which can measure both high and low tensions, the adsorption properties of the surfactant Intan-100 at the bitumen/aqueous solution have been studied at 30,60 y $75{ }^{\circ} \mathrm{C}$. The spinning drop technique requires to enhance the density difference between the oleic and aqueous phase. This was accomplished in two different ways: by diluting the bitumen with $10 \%$ Xylene by weight or by using Deuterium Oxide instead of water. Comparison with literature data on this particular surfactant allowed to conclude that dilution with Xylene strongly affects the adsorption and the critical micelle concentration in this system, while no appreciable changes have been found in the case of Deuterium Oxide.

In experimental studies of the interfacial properties of extra-heavy crude oils the use of heavy water is definitely to be preferred over dilution with aromatic solvents, even if very little is known about the effects of $\mathrm{D}_{2} \mathrm{O}$ on the adsorption and solution properties of surfactants. Increasing applications of Deuterium Oxide in interfacial and colloidal science, such as Nuclear Magnetic Resonance, neutron scattering and tensiometry, should promote a higher interest towards this interesting aqueous solvent.

\section{Acknowledgements}

We want to thank Geraldo A.S. Ribeiro for the suggestion of the use of Deuterium Oxide, and PDVSA-Intevep for the sponsorship of this work and permission to publish it. 
H.T.M. Vinagre and D.D. Joseph were supported by funds from the Engineering Research Program of the Office of Basic Energy Sciences (DOE), from the NFS (CEBT) and ARO (math).

\section{References}

[1] A. Bhardwaj, and S. Hartland, J. Dispersion Sci. Technol., 14 (1993) 87.

[2] Rosen M.J., Surfactants and Interfacial Phenomena, $2^{\text {nd }}$ ed., John Wiley \& Sons, New York, 1989.

[3] O. Möbius and R. Miller (Eds.), Studies in Interface Science, Vol. 6, Elsevier, Amsterdam, 1998, pp. 187-238.

[4] S. Hartland, Axisymmetric fluid-liquid interfaces: tables giving the shape of sessile and pendant drops and external menisci, with examples of their use, Elsevier Scientific Pub. Co., Amsterdam, 1976.

[5] Ref. 3, pp. 242-276.

[6] A. Pandit, C.A. Miller and L. Quintero, Colloids \& Surfaces, A: Physicochemical and Engineering Aspects, 98 (1995) 35.

[7] R.A. Mohammed, M. Di Lorenzo, J. Mariño and J. Cohen, J. Colloid Interface Sci., 191 (1997) 517.

[8] E.E. Isaacs and K.F. Smolek, Can. J. Chem. Eng., 61 (1983) 233.

[9] H.M. Princen, I.Y.Z. Zia and S.G. Manson, J. Colloid Interface Sci., 23 (1967) 99.

[10] D.D. Joseph and L. Preziosi, J. Fluid Mech., 185 (1987) 323.

[11] B. Vonnegut, Rev. Sci. Instrum., 13 (1942) 6. 
[12] D.D. Joseph, M.S. Arney, G. Gilberg, G. Hu, D.A. Hultman, C. Verdier and H.T.M. Vinagre, J. Rheol., 36 (1992) 36.

[13] D.D. Joseph and D.A. Hultman, Spinning Drop Tensioextensiometer, United States Patent, Patent N. 5,150,607 (1992).

[14] Chemical Rubber Company, "CRC Handbook of Chemistry and Physics", $59^{\text {th }}$ Ed. 1978/79, CRC press (1978).

[15] I. Layrisse ans H. Rivas, J. Dispersion Sci. Technol., 5 (1984) 1.

[16] J. Mariño, personal communication, 1995.

[17] N.J. Chang and E.W. Kaler, J. Phys. Chem., 89 (1985) 2996.

[18] W. Binana-Limbelé and R. Zana, J. Colloid Interface Sci., 121 (1988) 81.

[19] M.J. Schick, Journal Colloid Science, 17 (1962) 801.

[20] Ref. 2, p. 83.

[21] Ref. 3, p. 141. 
Table 1: Coefficients used in equation (2)

\begin{tabular}{|l|c|c|c|c|}
\hline Fluid & $\mathrm{C}_{0}$ & $\mathrm{C}_{1}$ & $\mathrm{C}_{2}$ & $\mathrm{C}_{3}$ \\
\hline CNR bitumen & 1018.70 & -0.63386 & 0 & 0 \\
\hline $\mathrm{CNR}+10 \%$ Xylene & 1006.30 & -0.65722 & 0 & 0 \\
\hline $\mathrm{H}_{2} \mathrm{O}$ or Intan-100 solutions & 1000.039 & 0.016947 & $-5.875 \mathrm{E}-03$ & $1.5522 \mathrm{E}-05$ \\
\hline $\mathrm{D}_{2} \mathrm{O}$ & 1104.963 & 0.166470 & $-8.09874 \mathrm{E}-3$ & $2.28966 \mathrm{e}-05$ \\
\hline
\end{tabular}

Table 2. Summary of experimental data from our experiments

\begin{tabular}{ccccc}
$\begin{array}{c}\mathrm{T} \\
\left({ }^{\circ} \mathrm{C}\right)\end{array}$ & $\begin{array}{c}\Gamma_{\infty} \\
\left(\text { moles } / \mathrm{cm}^{2}\right)\end{array}$ & $\begin{array}{c}\text { Area/molecule } \\
\left(\AA^{2}\right)\end{array}$ & $\begin{array}{c}\text { C.M.C. } \\
\left(\text { moles } / \mathrm{cm}^{3}\right)\end{array}$ & $\begin{array}{c}\gamma_{\mathrm{CMC}} \\
(\mathrm{mN} / \mathrm{m})\end{array}$ \\
& \multicolumn{4}{c}{ Bitumen+Xylene/ $\mathrm{H}_{2} \mathrm{O}+$ Intan-100 } \\
30 & $1.1 \times 10^{-10}$ & 144 & $5.0 \times 10^{-8}$ & 2.7 \\
60 & $1.0 \times 10^{-10}$ & 166 & $6.0 \times 10^{-8}$ & 1.8 \\
75 & $1.2 \times 10^{-10}$ & 132 & $5.0 \times 10^{-8}$ & 1.4
\end{tabular}

Bitumen / $\mathrm{D}_{2} \mathrm{O}+$ Intan-100

30

60

75

30
112

97

112
$1.2 \times 10^{-7}$

$1.0 \times 10^{-7}$

$1.7 \times 10^{-7}$

$1.5 \times 10^{-10}$

$1.9 \times 10^{-10}$

Air/ $\mathrm{H}_{2} \mathrm{O}+$ Intan- 100

86

$9.0 \times 10^{-8}$
37.0

3.7

2.1

1.4 
Figure 1A: Schematic representation of the components of the spinning drop tensiometer.

Figure 1B: Photograph of the spinning drop tensiometer.

Figure 2: Interfacial tension vs. temperature between CNR bitumen $+10 \%$ Xylene and water, CNR bitumen and water, CNR bitumen and heavy water.

Figure 3: Adsorption Isotherm of Intan-100 at the bitumen+Xylene/water interface at $30{ }^{\circ} \mathrm{C}$.

Figure 4: Adsorption Isotherm of Intan-100 at the bitumen+Xylene/water interface at $60{ }^{\circ} \mathrm{C}$.

Figure 5: Adsorption Isotherm of Intan-100 at the bitumen+Xylene/water interface at $75^{\circ} \mathrm{C}$.

Figure 6: Adsorption Isotherm of Intan-100 at the bitumen /heavy water interface at $30{ }^{\circ} \mathrm{C}$.

Figure 7: Adsorption Isotherm of Intan-100 at the bitumen /heavy water interface at $60{ }^{\circ} \mathrm{C}$.

Figure 8: Adsorption Isotherm of Intan-100 at the bitumen /heavy water interface at $75^{\circ} \mathrm{C}$.

Figure 9: Adsorption Isotherms of Intan-100 at the air /heavy water interface at 30, 60 and $75^{\circ} \mathrm{C}$ (the lines are guides for the eyes).

Figure 10: Adsorption Isotherms of Intan-100 at the air $/ \mathrm{D}_{2} \mathrm{O}$ and air/ $\mathrm{H}_{2} \mathrm{O}$ interface at 30 ${ }^{\circ} \mathrm{C}$. 


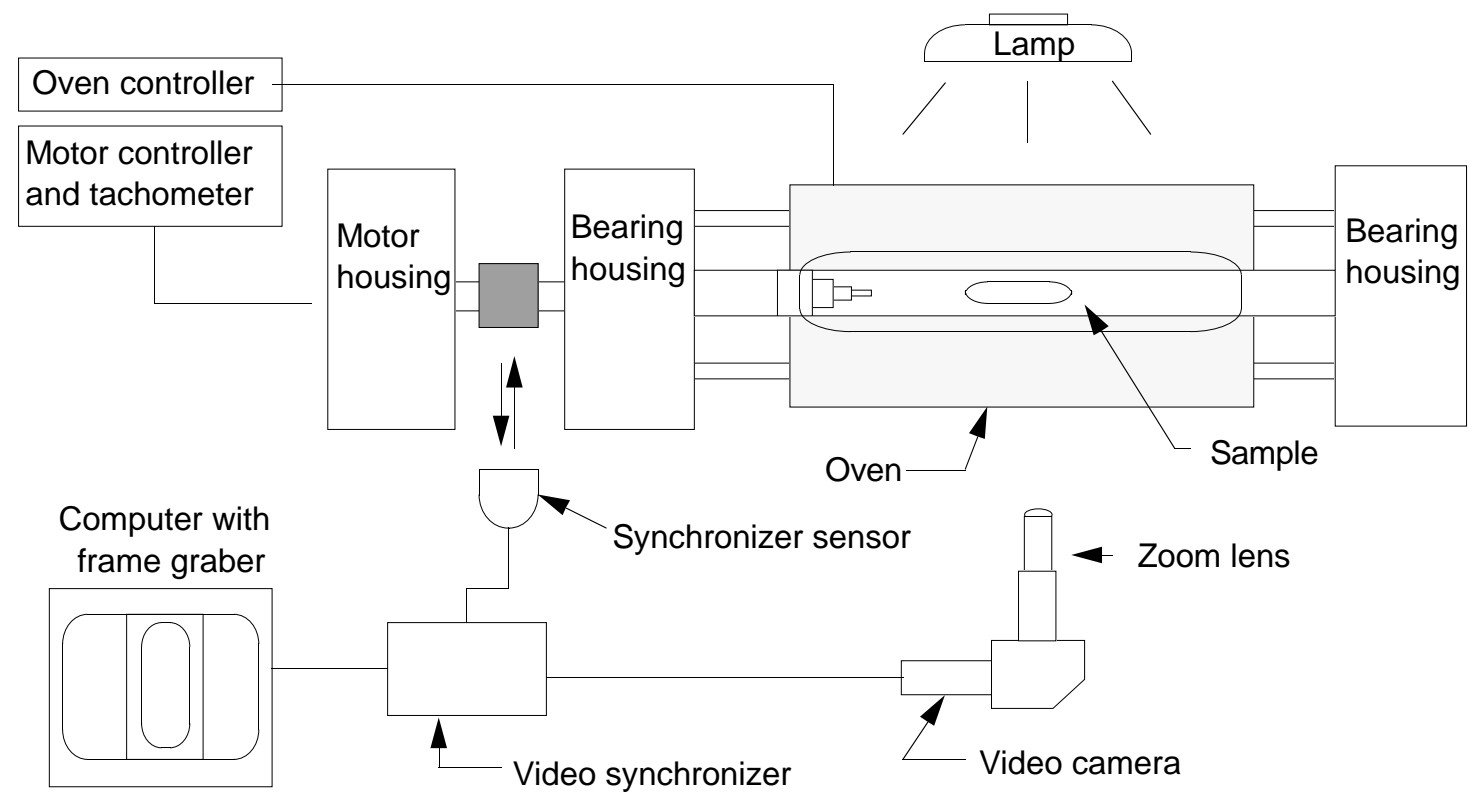

Figure 1A

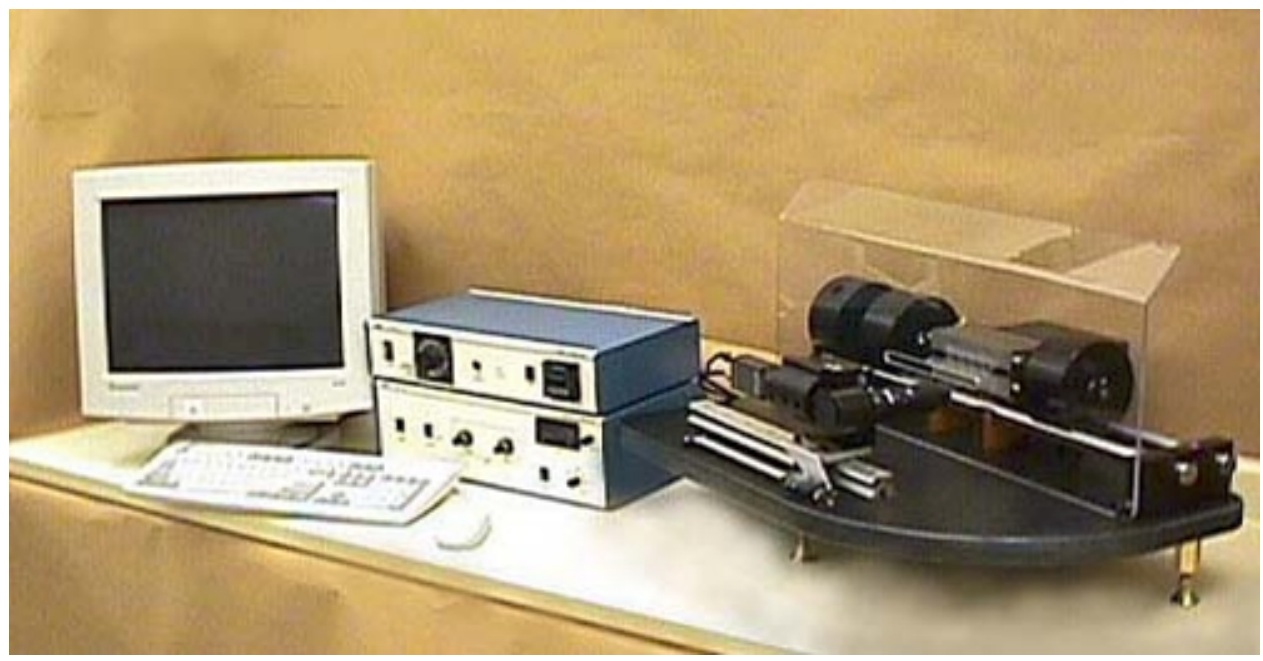

Figure 1B 


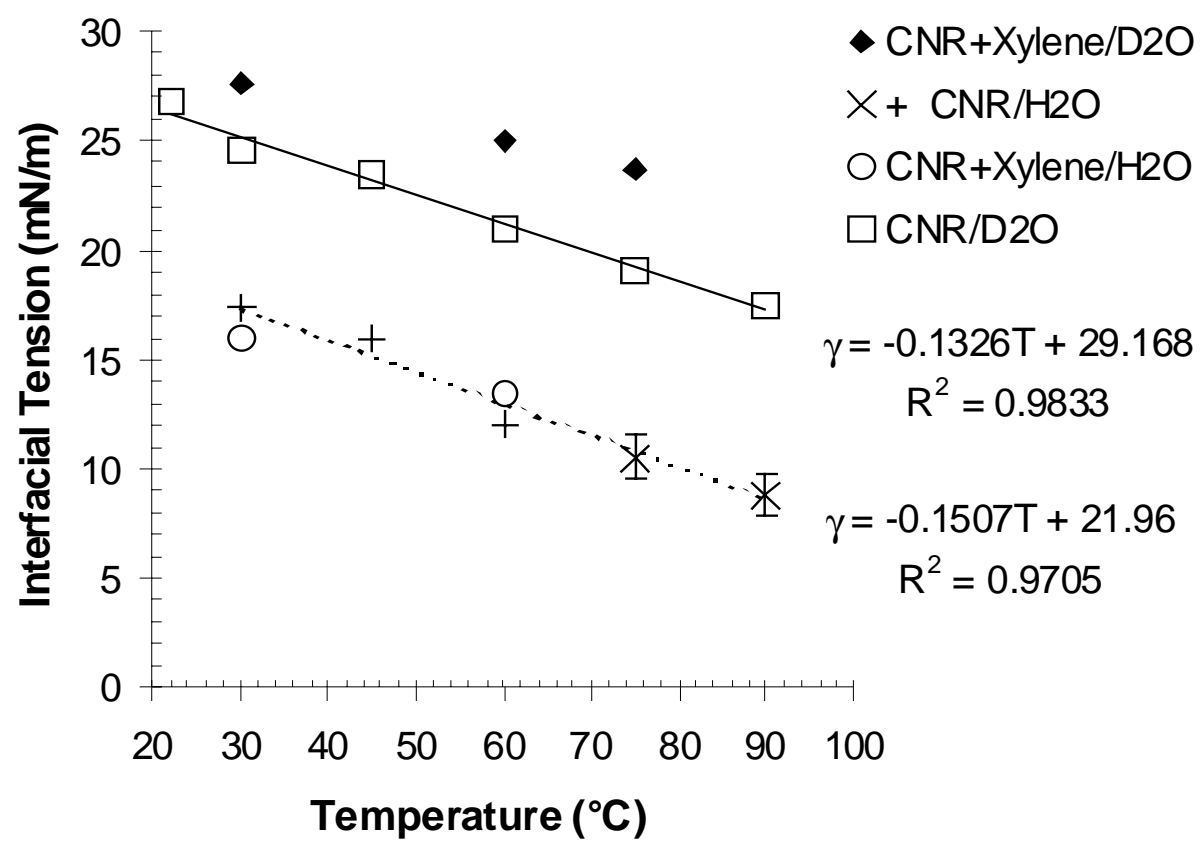

Figure 2 


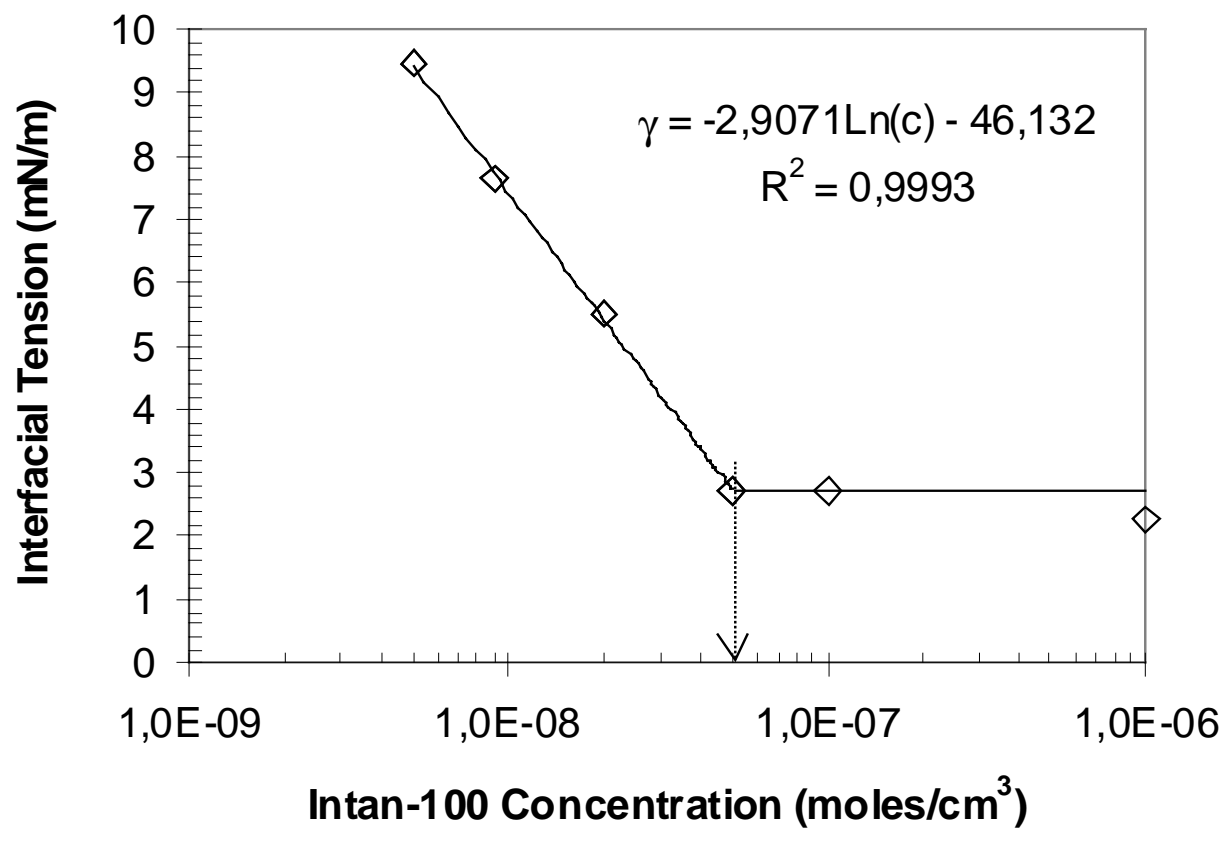

Figure 3 


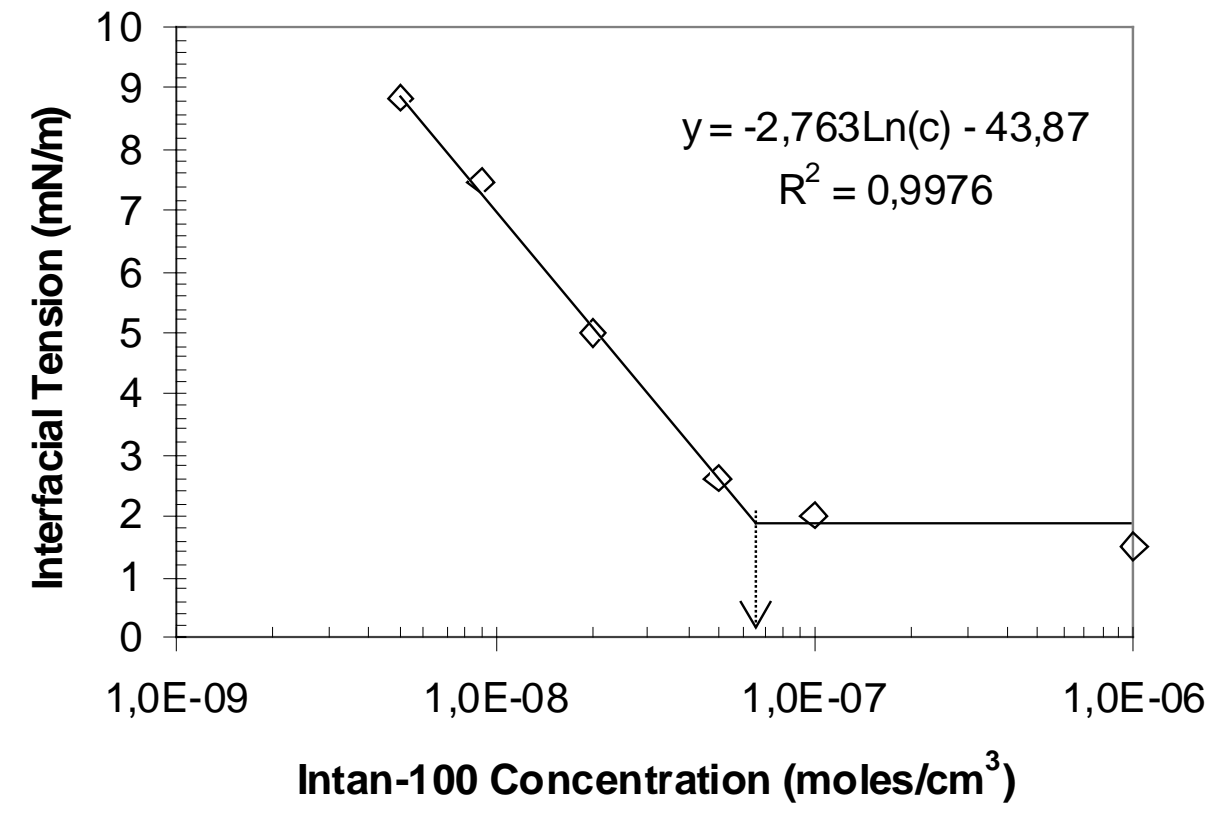

Figure 4 


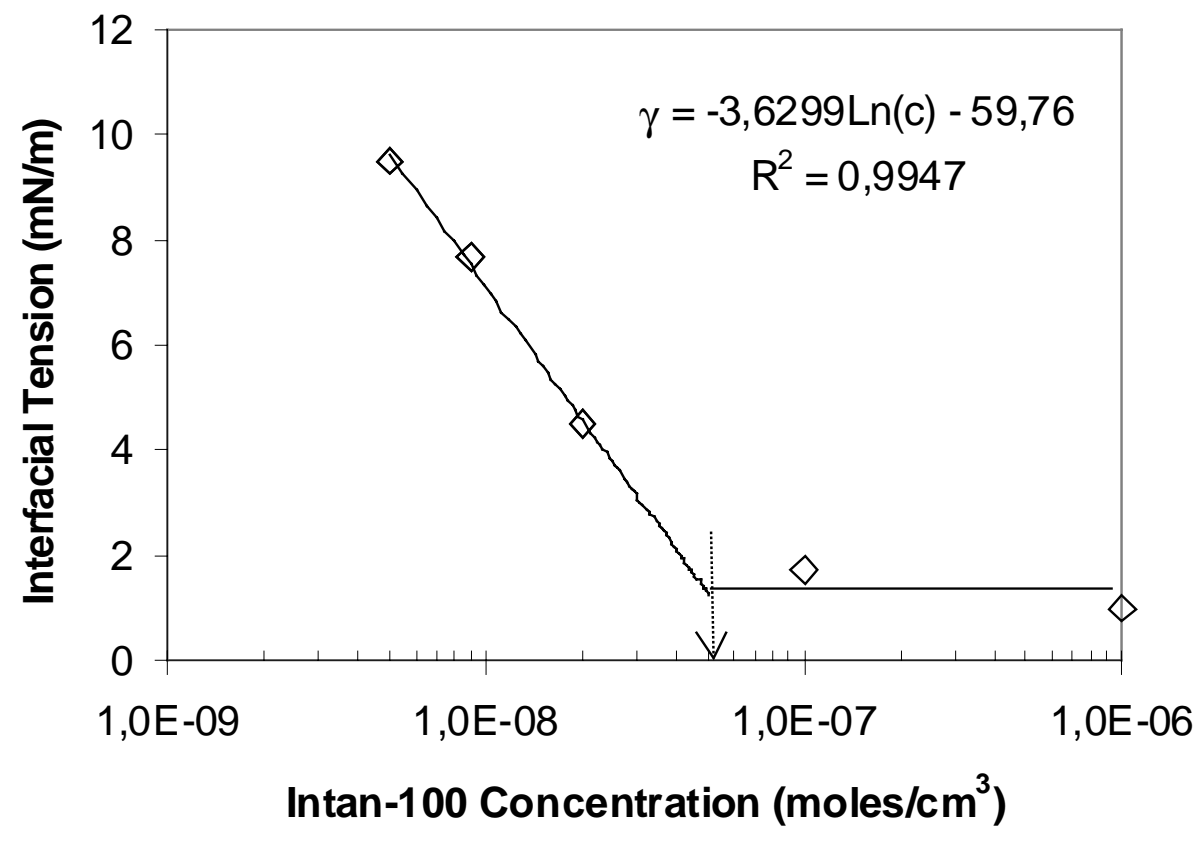

Figure 5 


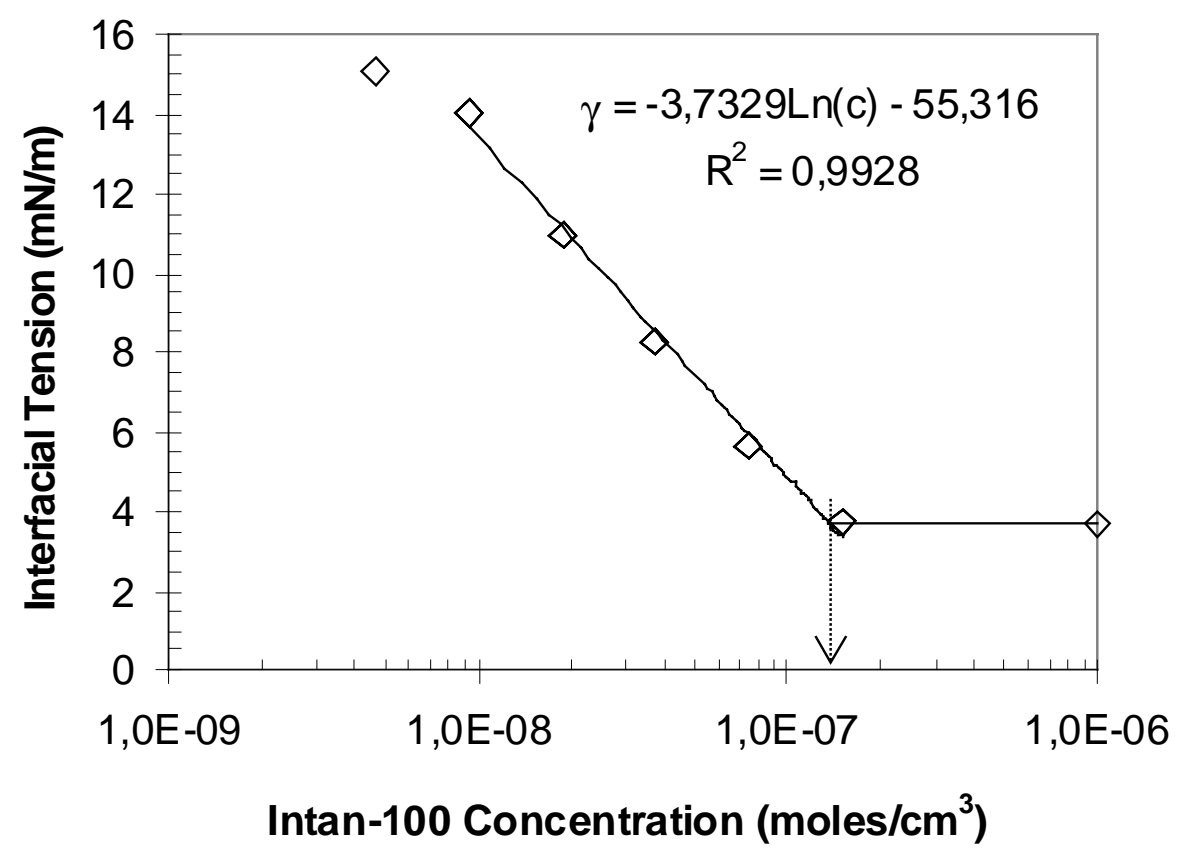

Figure 6 


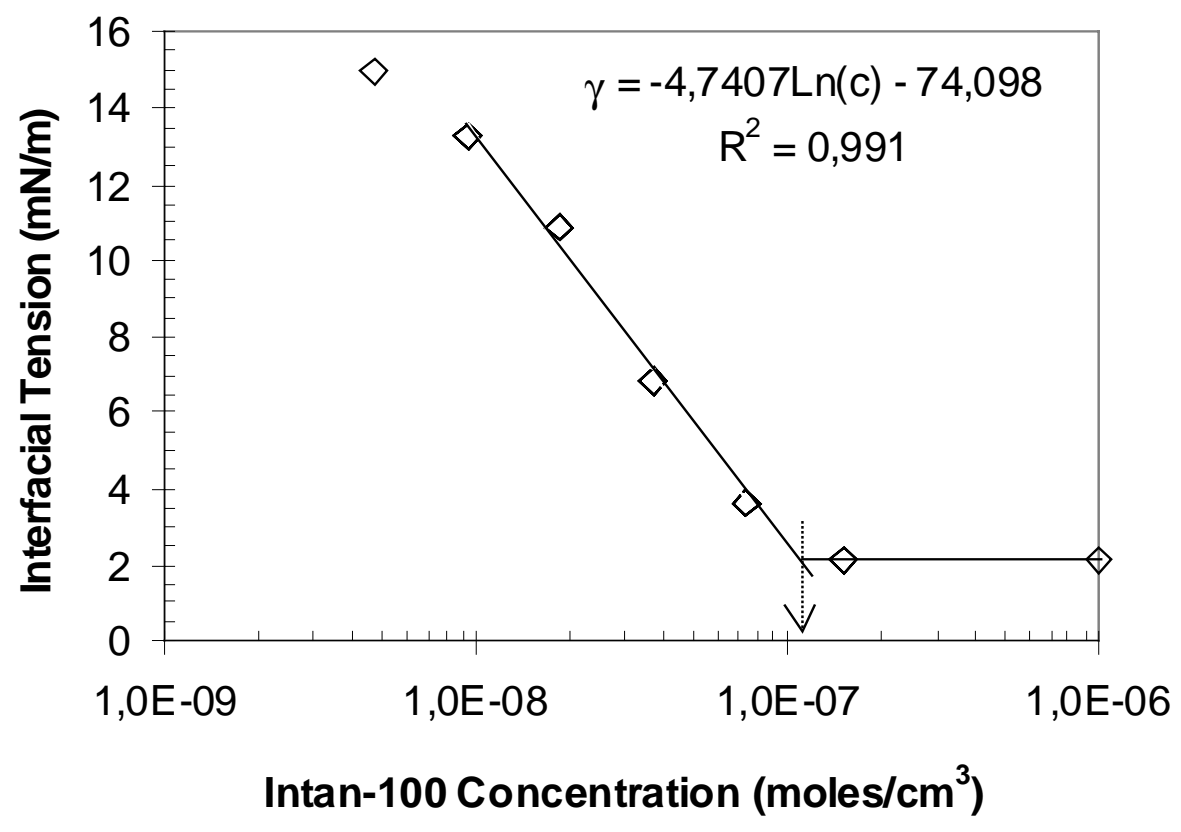

Figure 7 


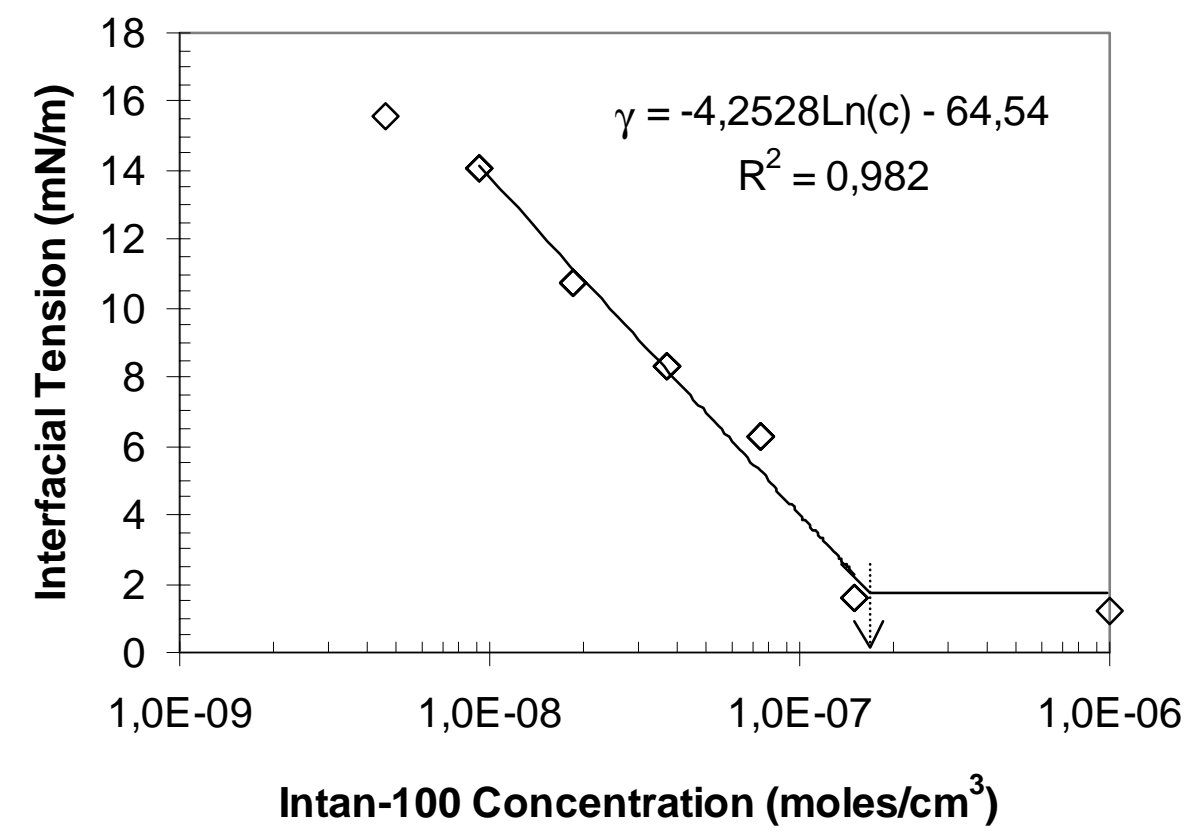

Figure 8 


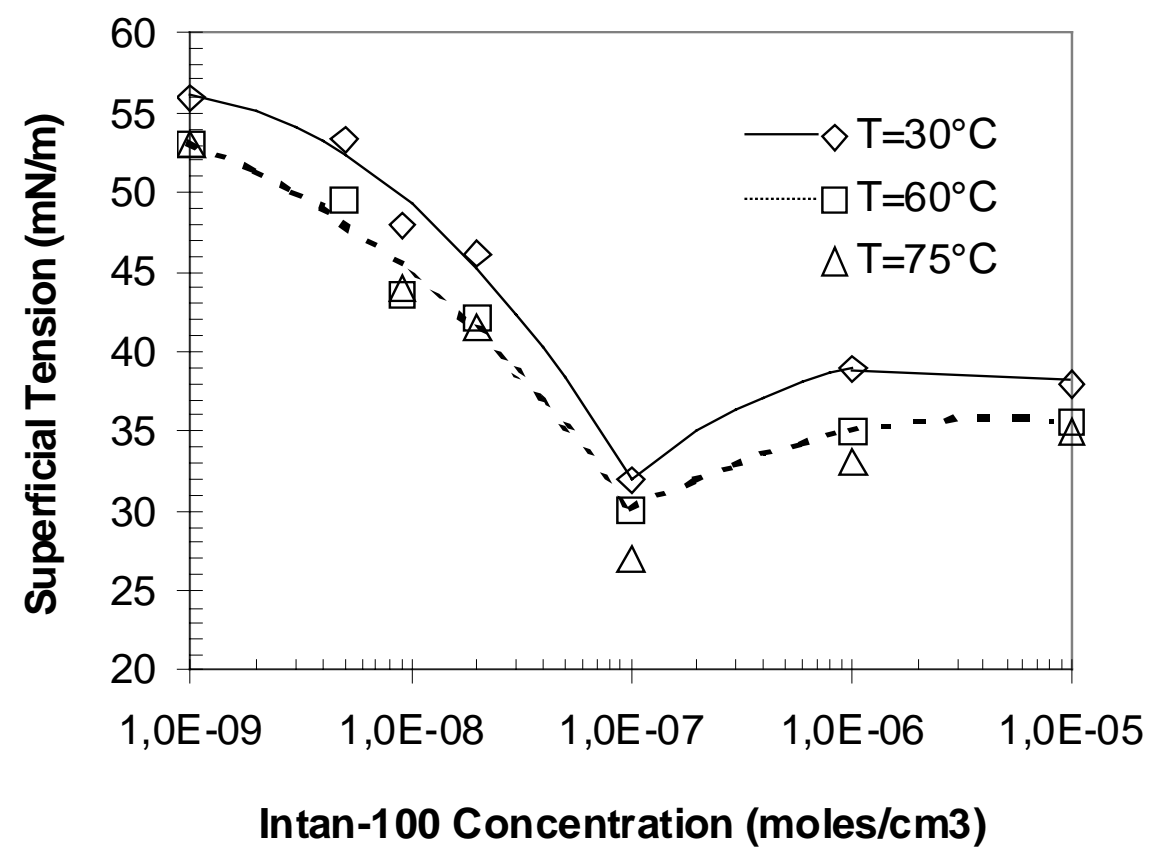

Figure 9 


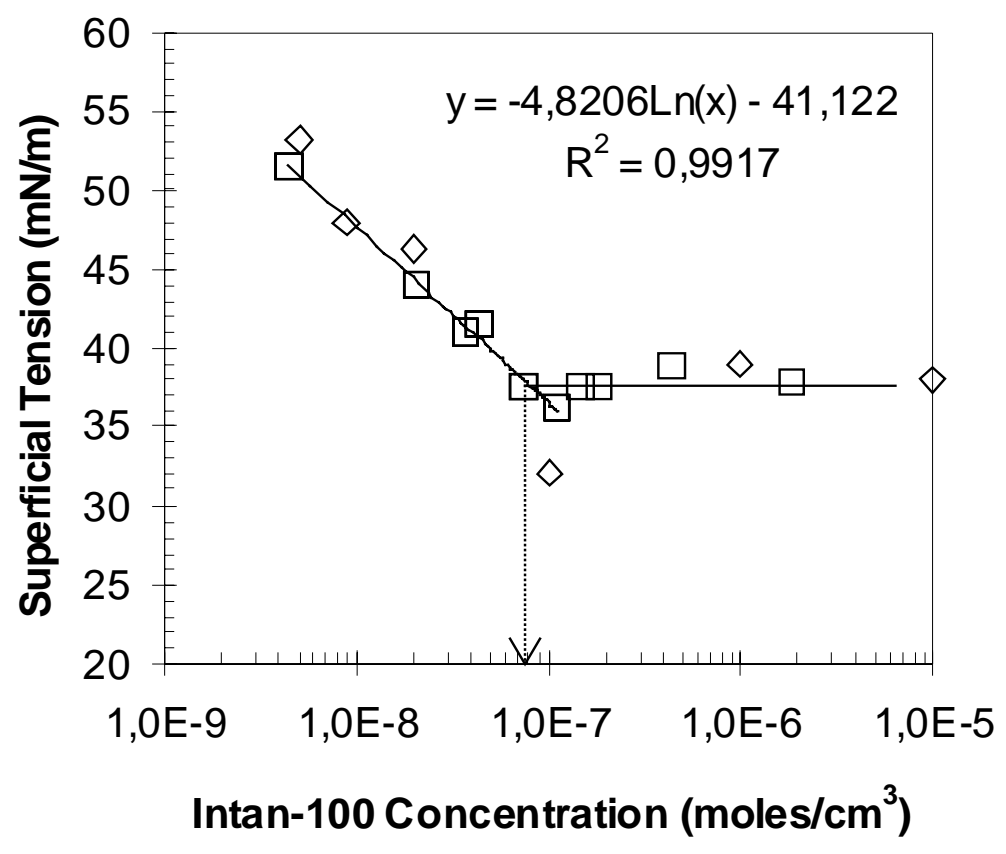

Figure 10 